\title{
Architectural Design Review Based on Animal Architecture and Biogas Productions
}

\author{
Mozhgan Heidari ${ }^{1}$ and Mahmud Rezaei ${ }^{2}$ \\ ${ }^{1}$ Master of Architecture, Faculty of Arts and Architecture,Islamic Azad University, \\ Central Tehran Branch, Department of Architecture, Tehran, Iran. \\ ${ }^{2}$ Assistant Professor and Faculty Member, Islamic Azad University, \\ Central Tehran Branch, Faculty of Arts and Architecture, Tehran, Iran.
}

DOI: http://dx.doi.org/10.13005/bbra/1943

(Received: 19 June 2015; accepted: 11 August 2015)

This article describes animal architecture as a multi-disciplinary field of bionic science and organic architecture which is recently popularized as one of the architectural design methods. By reviewing design procedures this study aims to organize a new way of design beyond visual analogies per se. The main question proposed in this paper is then 'what are the unique features of animal architecture methodology?' In addition, the paper explores design methodologies to answer 'how animal architecture method might be used beyond formal, visual and non-functional applications? For years several authors have proposed natural, organic and biological analogies in architecture. Even though designers have always been inspired by nature and employed animal analogies until recent periods, the non-formal aspects of this approach are not clearly addressed yet. While this study refers to organic and natural designs the authors focus more on architecture inspired by animals' life. In this research biogas as a form of renewable energy derived from animals is described briefly. Furthermore, it is suggested how biogas might be applied as a non-formal analogy in design process. This applied research is conducted qualitatively by using descriptive and analytic methods and the data are broadly obtained from original documents. To verify this method some case studies are compared with the principals of animal architecture. Based on the results, it can be concluded that a new classification of animal architecture is required. This paper shows that animal architecture is not a unique, exclusive method in architecture. In fact, it is a subcategory of analogy method in which analogy happens through animal bodies or their nests. Beyond mere formal and visual approaches, this method may act as a functional approach. For example, the use of biogas in an architectural project might act as an inspiration and source for sustainable design. Moreover, different types of architectural constructions related to animal lives are recommended to be covered by this method.

Key words: Architecture design methodology, Natural and animal Architecture, biological and Organic design, Biogas.

The present research seeks to examine form of architecture matched with nature of animals in architecture which is also known as animal architecture or architecture inspired by nature animals (Bahaman \& Perez, 2009). The questions

* To whom all correspondence should be addressed. which have been considered in the present research are as follows: what are a variety methods for architecture matched with animal structures? What is the position of animal architecture among natural, organic and biological architecture methods? How animal architecture can be separated from other design methods? What is a unique point in animal architecture? How a meta-form analogy can be 
found in animal architecture which helps for design?. The relationship between biology and architecture is a long relationship. Indeed, animal architecture has not started since the 1970s regarding the ecological architecture, but role of live agent, biology and form of animals and plants in architecture dates back to the long lost past. However, such architecture seems weird apparently; it belongs to important issue of natural architecture and enjoys biological similarity which dates back to long lost past (Bahamon \& Pérez, 2011, p. 10).

Nature is influential in most of the strategies ending in creativity of architecture, appeared as a strong tool for inspiration. Among different laws of nature, it can assume law of gravity, law of minimum energy efficiency, law of attraction, law of habitation, law of life cycle associated to architecture. Presence of nature is clear in metaphor, imitation and variability of form and materials (Antoniades, 2011, pp. 421-427).

The ones who have referred to natural, organic and biological analogies in architecture include Vitruvius (1414), Leon Battista Alberti(1450), Marc. Antoine laugier(1753), Antoine kremer (1788), Eugène Viollet-le-Duc (1863-1879), Frank Lloyd Wright (1908, 1932, 1954), Sant‘Elia (1914), Peter Collins (1965) and Philip Stedman (1979)(Rezaei, 2014, p. 277).

Karl von Frisch, the inventor of animal architecture, has become Nobel Prize winner in 1974. Karl von Frisch (1886-1982) in his studies indicated capabilities of some animals in creation of construction structures with masterpiece technology (Bahamon \& Pérez, 2011, pp. 4-10).

Otto von Frisch and Karl von Frisch (1974) have proposed the possibility to use structure of some animals in creation of architecture. In addition to ordinary classification for design. Mike Hensel has considered innovative design for architecture taken from nature and animals. Bahamon \& Pérez(1984) knew the relationship between building and biology as the origin for the design matched with nature. They have examined anatomical structure of animals (armor, hair, skin, crabs, snails, shells, scales), animal constructive structure (underground cavity , spider' web, beaver, bird's nest), social animal constructive structure(anthills, beehive, coral), and their temporary structures(marsupial, pupae) and suggest that nature basically provides not only construction materials but also the construction patterns(Rezaei, 2014, p. 212).

At the area of animal architecture, the architects such as Renzo Piano, Norman Foster, Frank Gehry, and Santiago Calatrava have used animal -shaped structure in substantial number of their newest patterns. Further, some scholars such as Bahamon, Johann plasma, Mike Hensley and Karl von Frisch have been found as prominent scholars at the area of animal architecture. However the approach matched with animal architecture has been proposed by many scholars, no one has referred to the details of method and evolution stages of such architecture in a cohesive way. Further, comparison of this approach with rest of approaches has not been made aiming at discovering distinctive feature of this method, so that designers' emphasis has been seemed apparent. It can exploit from animal architecture via fundamental methodology.

Hence, the main purpose of this research is to expand use of analogy from form to metaform. The main purpose of this study is to access to leading origin of design method for animal architecture and access to the features which differentiate this design method from rest of methods. In this research however organic and natural design has been considered, the animal aspects of such design at contemporary age in western architecture have been discussed. The samples under study in this research have been represented as abstract in tables.

In following, research method will be described. Then, theoretical background and concepts associated to idea of animal architecture will be represented in details. Then, through the proposed method, a huge criticism will be put on this method. Then, biogas will be described as one of the methods to use renewable energies taken from animals. Hence, in this section, chemical and structure and how biogas is produced, have been described. In next section, it is discussed how biogas in architecture as a meta-form analogy method can engage in creation of architecture. Ultimately, the conclusion will be proposed.

\section{Research method}

The data have been collected via qualitative method based on library and documentary studies. Firstly, a variety of design 
method for organic architecture and their relationship with animal architecture have been examined. The fundamental, applied and descriptive method has been considered as the research method. Data have been collected through observation and extraction from documents and the research has been conducted through case study and comparative analysis using summarization of qualitative data. A variety of samples based on theorists' ideas have been examined and analyzed that their elaboration has been neglected in the present research. These samples have been extracted from the texts pertaining to animal architecture, that the authors have made an attempt to intervene their personal view in selection of samples. In this selection, an attempt has been made to select more practical samples to specify probable meta-form applications in the sample. In this regards, inductive research method is taken into consideration. With regard to consultation with scholars at the field of civil and environmental engineering, the contents pertaining to biogas have been formulated and examined and how to use the wastes to produce biogas as a renewable energy resource in animal architecture have been extracted and elaborated based on analogy.

\section{Theoretical background \\ Nature and architecture}

From the very beginning till today, the man has been in interaction with nature that one of its results has been inspiring and copying from nature for living. Adjustment with nature and use of natural patterns are effective as a source for creation of concept of architecture (Bahamon \& Perez, 2011, p. 7-10). In recent decades, under extension of the man's recognition from nature and animals and inspiration from them, an issue has been started in architecture, urbanization and other trends regarded with bionic, organic and biological architecture, called with animal architecture.

Vitruvius has put an emphasis on analogy between the order of the human body and nature under this assumption that the building is specifically for the man and use of order in building is the same of the order governing nature. Leon Battista Alberti defines creation of architecture as the analogy with certain order. Laugier and Quatremere knew the man's primitive hut at each period inspired from analogy with nature at that period (Rezaei, 2014, pp. 273-274).

Hence, inspiration from nature is one of the important approaches for design. Use of nature has been of great important at all arts including architecture. Exploitation from nature has paved the way through five ways: 1-measurment of criterion of buildings, 2-display of nature, 3learning from nature, 4- Every living thing is a designer, 5-exploitation from natural models (Mahdinejad et al. 2012, p. 62).

\section{Bionic Science}

Bionic has been taken from combination of two words "biology" and "technique", meant use of organs made by nature. The term "bionic" has been proposed by Jack. A. Style in 1958 from aviation sector in an Air Force Base in Dayton, Ohio (Taghizadeh \& Bastanfard,2012,p.10).

Emergence of bionic science in nature has been targeted in exploitation from optimal and distinctive solutions in nature. Bionic science was divided into several subsets by the passage of time, that the leading one is named "biomimicry" targeted in studying systems, patterns, behaviors and forms of living things to create new innovative products. This issue is often followed by measurement of optimal behavior of animals and plants to use their information in design of new products (Pourtalebi, 2012, pp. 1-2).

Most of man's modelings have been inspired from nature throughout the history. Among the scientific projects at the area of bionic, Leonardo da Vinci considered bionic for the first time to construct an aeromobil and study birds in flight, however he failed to accomplish this, his effort has been recognized as the earliest effort in line with biometric (Sadri, 2014, p. 93).

\section{Organic architecture}

Organic architecture implies a philosophy in architecture. Notion of organic architecture has rooted in romantic philosophy. Indeed, classical movement seeks dominance on nature, yet Romantic Movement seeks admiration of nature. Organic architecture was developed by Frank Furness and Louis Sullivan in U.S, yet the climax of evolution of this theory can be found at the first half of the $20^{\text {th }}$ century in Frank Lloyd Wright's plans and writings (Ghobadian, 2008, pp. 63-65).

Eugène Viollet-le-Duc has introduce the metaphor of organic in architecture taken from natural forms of anthill, bird nest, honeycomb, or a 
beaver lodge besides the metaphors for machine(Rezaei, 2014, p. 274).

Natural forms serve as curved forms that less likely represent straight lines; such forms are called organic forms. Organic design as a branch of bionic not just due to visual perceptions but also a wide range of perceptions results in creating emotions.

Sensations such as cold and heat, olfactory, tactile and auditory raise fundamental experiences that have negligent difference among different cultures (Pourtalebi, 2012, p. 2).

In point of view of Frank Lloyd Wright, organic architecture implies expansion of nature and its principles, i.e. the linkage between a building and its surrounding environment is in a way that a building must be settled in environment. Frank Lloyd Wright has described this issue in this way: the building must be manifested in a way to growth from floor and appears in a form matched with surrounding environment. The second concept for the linkage between organic architecture and nature includes the principles derived from nature. In point of view of Frank Lloyd Wright, nature has been a principle for understanding and integrating work of an architect. Simplicity of organic architecture has been a lesson and purpose at the stage of combination and form. In his point of view, natural forms assume as tree, flower, plain, forest and farms, because they are not fabricated or accidental. Yet, none of them has a decorative aspect leading to disturb. Ultimately, Frank Lloyd Wright conducted meaning of common use of nature towards architecture elements regarding nature (cruze, 2012, 29-30).

Antonio Sant'Elia has not known natural metaphor limited to human form and natural materials and has separated organic combination due to more cohesion and integration in its elements from the metaphor for machine combination. Philip Steadman has classified biological analogies to organic, classificatory, anatomical, ecological and Darwinian analogies (Rezaei, 2014, pp. 274277). Natural phenomena arrangements embed in three classifications including non-living natural structures, plant structures and animal structures (Sharghi \& Ghanbaran, 2012, pp. 111-112).

\section{The architecture matched with nature of animals}

Bahamon \& Pérez have classified the architecture matched with nature of animals to four groups:
(a) Animal anatomical structures
(b) Animal constructive structures
(c) Social animal constructive structures
(d) Temporary animal structures

\section{Animal anatomical structures}

This classification refers to outer covering of animals including skin and other protective parts that cover the animal's body and encompasses the samples in architecture that have been accomplished through exploitation from clams, snails, Bernard Hermite, scales , hair and skin.

In general, the term "shell" is used to define a wall which encompasses the interior space and separates it from outer space. Here a question is asked: whether architecture is the third covering of man or not. There are numerous commonalities between architecture and covering system of animal, including heat exchange and necessity for information exchange and liquid and gas substances (Bahamon \& Pérez, 2011, p. 12).

What is obvious in this classification lies on this fact that Bahamon \& Pérez have put an emphasis on the shells used in architecture through exploitation from outer covering of animal and have not referred to interior layers such as skeleton of animals.

\section{Animal constructive structures}

In this classification, how to use behavior style of animals has been considered in construction of the structures such as bird's nests, spider, nest -building techniquesbeaver loges, construction of underground cavities by terrier dog as a natural pattern in architecture patterns.

\section{Social animal constructive structures}

Tendency to social life in organic world has raised construction of complicated systems which comes to realize by insects, drawn into attention from biological and architectural perspectives. The samples like what in nest of termites, beehives and lifestyle of corals represents the ideas for natural world of animals in architecture.

\section{Temporary animal structures}

This classification refers to temporary buildings in nature that pave the way for generation of some animals out of the mother's body for developing fetus and/or protecting babies. Fetus of some 
animals like most of mammals grows in mother's womb and takes the required food for formation of their bodies since the birth. Another group is egglaying animals that their generation system has been organized based on egg-laying in an environment out of the animal's body. The fetus continues growing inside the egg till opening the egg (Bahamon \& Pérez, 2011, p. 164). The patterns such as marsupials like the kangaroo, pupae, eggs, including eggs of other birds, eggs of fish and amphibians are considered in this classification which is inspiring in architecture (ibid, pp. 164186).

Revision and criticism of architecture method matched with nature of animals

Summary of the classification by Bahamon \& Pérez which was mentioned previously has been presented in table 1 as follow:

However Bahamon \& Pérez have

Table 1. The classification for methods for exploitation from architecture matched with nature/ source: (author)

\begin{tabular}{|c|c|c|c|}
\hline Row & Author & Text/year & Classification \\
\hline 1 & Vitruvius & Ten Books of Architecture1414 & $\begin{array}{l}\text { The analogy between order of man's body and } \\
\text { nature and building due to two reasons: the } \\
\text { building is for the man; use of analogy in } \\
\text { building is the same as the order existing in } \\
\text { nature. }\end{array}$ \\
\hline 2 & Philip Steadman & $\begin{array}{l}\text { The Evolution of Design : } \\
\text { Biological analogy in } \\
\text { architecture and applied arts } \\
1979\end{array}$ & $\begin{array}{l}\text { Organic } \\
\text { Classificatory } \\
\text { Anatomical } \\
\text { Ecological } \\
\text { Darwinian }\end{array}$ \\
\hline 3 & Bahamon \& Pérez & $\begin{array}{l}\text { Inspired by Nature Animals: } \\
\text { The building biology } \\
\text { connection } 2010\end{array}$ & $\begin{array}{l}\text { Animal anatomical structures } \\
\text { Animal constructive structures } \\
\text { Social animal constructive structures } \\
\text { Temporary animal structures }\end{array}$ \\
\hline
\end{tabular}

Table 2. A modern structure for architecture method inspired by nature animals/ source: (Heidari, 2015, p. 100)

\begin{tabular}{|c|c|c|c|c|c|c|}
\hline \multirow{6}{*}{$\begin{array}{c}\text { Nature } \\
\& \\
\text { Architecture }\end{array}$} & \multirow{6}{*}{$\begin{array}{c}\text { Animal } \\
\text { Architecture }\end{array}$} & Utilization & \multicolumn{2}{|c|}{ Classification } & Analogy & Sample \\
\hline & & \multirow{4}{*}{$\begin{array}{l}\text { Formal } \\
\text { based }\end{array}$} & \multirow[t]{2}{*}{$\begin{array}{l}\text { apparent } \\
\text { form }\end{array}$} & $\begin{array}{l}\text { the anatomical } \\
\text { structure of animal }\end{array}$ & \multirow[t]{2}{*}{$\begin{array}{l}\text { apparent form } \\
\text { of animals }\end{array}$} & $\begin{array}{c}\text { Clams, snails, Bernard } \\
\text { Hermite, scales, hair, skin, } \\
\text { bones and skeletons }\end{array}$ \\
\hline & & & & $\begin{array}{l}\text { temporary building } \\
\text { structures of animals }\end{array}$ & & Marsupial, pupa and eggs \\
\hline & & & \multirow{2}{*}{$\begin{array}{l}\text { Behavioral } \\
\text { methods in } \\
\text { nests }\end{array}$} & Individual & \multirow{2}{*}{$\begin{array}{c}\text { Function of } \\
\text { animals in nest- } \\
\text { building }\end{array}$} & $\begin{array}{l}\text { Nest, Spider web, Castor } \\
\text { Terrier dog } \\
\end{array}$ \\
\hline & & & & Social & & $\begin{array}{l}\text { Vespiary, Hive, Termite } \\
\text { Nest, Coral }\end{array}$ \\
\hline & & $\begin{array}{l}\text { non-formal } \\
\text { based }\end{array}$ & \multicolumn{2}{|c|}{ Features ending in natural cycle } & $\begin{array}{c}\text { Features of } \\
\text { animals which } \\
\text { result in } \\
\text { self-efficacy in } \\
\text { natural cycle }\end{array}$ & $\begin{array}{c}\text { Energy production from } \\
\text { animal wastes atRiding } \\
\text { Sch }\end{array}$ \\
\hline
\end{tabular}

presented little classification, exploitation from architecture method inspired by nature animals is classified to two more general sections: analogy with apparent form of animals, analogy with nest of animals, under which anatomical structure of animals and temporary building structures of animals pertain to placement area of fetus and apparent form and building structures of animals and building structures of animal communities pertain to analogy with nest. Further, Bahamon \& Pérez have not referred to role of animals' skeleton and its effect on architecture structures in classification and examination of case studies, yet attention to skeleton structures of animals is an 
Table 3. Role of analogy in the samples exploited from apparent form of animals in architecture/ source: (Heidari, 2015, p. 90)

\begin{tabular}{|c|c|c|c|c|c|}
\hline Row & Name of building & Designer, place, time & $\begin{array}{l}\text { Role of } \\
\text { analogy }\end{array}$ & Figures & \\
\hline 1 & Bus station in Casar de Cacares & Justo Garcia Rubio/ Spain/ 2003 & Shell & & Role of \\
\hline 2 & Glas gow Science museum & $\begin{array}{l}\text { Building Design Partnership' } \\
\text { UK/ } 2001\end{array}$ & Snail & & in Architecture \\
\hline 3 & Torreviej a Park & $\begin{array}{l}\text { Toyo Ito \& Associates/ Spain/ } \\
2005\end{array}$ & Snail & & $\begin{array}{l}\text { inspired by } \\
\text { nature animals }\end{array}$ \\
\hline 4 & Brno Airport Terminal & $\begin{array}{l}\text { Peter Parolet/ Czech Republid } \\
2006\end{array}$ & Turtles & & \\
\hline 5 & SECC Conference Centre & Foster and Partners /UK /1997 & Turtles & & \\
\hline 6 & Conversion of a Windmill & Jose Gigante/ Portugal / 1995 & $\begin{array}{l}\text { Bemard } \\
\text { Hermite }\end{array}$ & & \\
\hline 7 & S aving the Bacon & FNP Architects/Germany/2004 & $\begin{array}{l}\text { Bemard } \\
\text { Hermite }\end{array}$ & & \\
\hline 8 & Hall West Gallery & UNS tudio/Seoul- Korea/ 2004 & Scale & & \\
\hline 9 & Laren House & $\begin{array}{l}\text { Monk Architects / Netherlands/ } \\
2005\end{array}$ & Hair & & $\begin{array}{l}\text { Role of } \\
\text { analogy }\end{array}$ \\
\hline 10 & Elephant Skin House & PPAG Architects / Avstria/ 2005 & Skin & & in Architecture \\
\hline 11 & Kiss the Frog & $\begin{array}{l}\text { MMW Architects/ Norway' } \\
2005\end{array}$ & Skin & & $\begin{array}{l}\text { inspired by } \\
\text { nature animals }\end{array}$ \\
\hline 12 & SH House & $\begin{array}{l}\text { Hiroshi Nakamura \& NPA } \\
\text { Architects/Japan/2005 }\end{array}$ & $\begin{array}{l}\text { Marsupi } \\
\text { al }\end{array}$ & & \\
\hline 13 & Plashet bridge & $\begin{array}{l}\text { Birds Portchmouth Russum } \\
\text { Architects/ UK/ } 2000\end{array}$ & Pupa & & \\
\hline 14 & Concrete-Pod & $\begin{array}{l}\text { Kazuya Morita Architecture } \\
\text { studio/J apan/ } 2005\end{array}$ & Egg & & \\
\hline 15 & Free University of Berlin & $\begin{array}{l}\text { Foster and partners/ Germany/ } \\
2004\end{array}$ & Egg & & \\
\hline
\end{tabular}

Table 4. Role of analogy in the samples exploited from behavioral style in animals' nests in architecture/ source: (Heidari, 2015, p. 91)

\begin{tabular}{|c|c|c|c|c|c|}
\hline Row & Name of building & Designer, place, time & $\begin{array}{l}\text { Role of } \\
\text { analogy }\end{array}$ & Figures & \\
\hline 1 & Vogelnest Observatory & Freie Architects / Germany/ 2001 & Nest & & \\
\hline 2 & Keenan Tower & Marton Blackwell / USA / 2000 & Nest & & le of \\
\hline 3 & Mur Island & Acconci S tudio/Austria/ 2003 & Spider web & & analogy \\
\hline 4 & River Restaurant & $\begin{array}{l}\text { Matti Ragaz Hitz Architects/ } \\
\text { Switzerland / } 2004\end{array}$ & Beaver & & in architecture \\
\hline 5 & Gruta das Torres & Sami Architects / Portugal /2003 & Terrier dog & & $\begin{array}{l}\text { Inspired by } \\
\text { nature animals }\end{array}$ \\
\hline 6 & Behive & Eric Owen Moss /US A / 2001 & Vespiary & & \\
\hline 7 & Izola Apartments & OFIS Architects/Slovenia/2006 & Hive & & \\
\hline 8 & Moore Apiary & Marlon Blackwell / USA / 1998 & Hive & & \\
\hline 9 & Davies Alpine Greenhouse & $\begin{array}{l}\text { Wilkins on Eyre Architects / UK } \\
2005\end{array}$ & Termite nest & & \\
\hline 10 & Hysteric Ballroom & Bube/ Netherlands / 2007 & Termite nest & & \\
\hline 11 & Coral City Island & Damian figveras/ Dubai / 2007 & Coral & & \\
\hline
\end{tabular}


inspiring source in the architecture matched with animal structures.

Role of skeleton members in animals' body assimilates to loading skeleton in a building. Any structure requires a structural skeleton for sustainability and balance. Skeleton structure of animals' body develops a series through tensile elements such as muscles and tendons and joints such as cartilage that the most comprehensive architecture does not reach to it (Sharghi, 2008, p. 112).

Role of skeleton members and body's skeleton serve as anatomical structure of animals that Bahamon \& Pérez have examined this classification pertaining to outer covering and shell such as clams, snails, cocoon-like cover such as Bernard Hermite crab , urchin, scales , hair, feathers and skin. Yet, anatomical structure of animals includes interior layers and skeleton in addition to cover and shell of animals.

Overview of approach of natural architecture concerning architecture method matched with animal structures and case studies studied in the present research indicates that to date such method in sake of loan shift disregarding biological dimensions has been used by designers and theorists (table 1-4). Further, the case studies under study indicate that the building which has been designed through form-shaped design have not been recommended for the architecture pertaining to animals such as schools and horse riding centers, livestock, zoos and Animal Care Centre. Animal architecture has been proposed in sustainable development and biodiversity issues to date. In addition, it can observe that the samples proposed in this method have passed a trend from top to down in sake of design trend, that notably use of this method has been accomplished with an emphasis on combination and integration.

On the other hand, role of analogy in the process of design is clear in each samples representing architecture matched with animals. It can consider the examined samples in analogy with a method of apparent form or a behavior in animals nest-building, such that the samples representing the architecture matched with animals' structures and how the analogy and inspiration have appeared, have been shown (tables 3 \&4).

Analogy implies the measurement of the credit level of form at the level of synthesis with regard to its answerability to phase components of analysis. To create his or her work, the designer makes analogies of different kinds between concrete to abstract phenomena. With regard to this concept, the designer develops the design considering the surrounding world and selecting a phenomenon which is similar to the favorable features of the project (Rezaei, 2014, p. 18).

Such analogy is the origin for all the design methods, and this goes true for the architecture matched with animals' structures.

Chris Abel has considered fifteen analogical models for design of architecture in two major classifications including formal analogies (spiritual, classical, military, utopian, organic, artistic, linguistic, commercial, identity, self-build models) and process analogies(scientific, systems, semiotic, legal) (ibid, p. 276). Animal analogy as a type of organic analogy will be considered in subset of Abel's form-shaped analogy.

\section{Design with use of renewable resources (biogas)}

Formal analogies have been more likely proposed and used in all the proposed cases and rest of cases representing the architecture inspired by nature animals. No theorist has discussed on non-formal use of this method. Yet, animal life has the features that can be used for favorable design in apparent way.

Even though today animal yards waste shit control in order to reduce amount of unfavorable smelling and environmental challenges has been mentioned as one of the problems in these yards, this problem can be used to supply energy. For instance, previously traditional -KaboutarKhaneh (towers for nesting birds) in Iran paved the way for fundamental use of architecture inspired by nature animals. Kaboutar-Khaneh has been traditional and cylindrical building for gathering manure of pigeons and other birds for agriculture consumptions (Heidari, 2015, p. 65). However, to date such issue has not been regarded and used in animal architecture, use of biogas as a source of renewable energies must be considered in architecture method matched with animal lives, regarding reduction of renewable sources and importance of energy issues.

Nowadays, with regard to low return on use of traditional methods, high cost for disposal of wastes and environmental pollutions, use of modern methods such as anaerobic digestion to 
produce biogas has become conventional. Biogas produced from the process of anaerobic digestion can be used as a renewable energy source similar to natural gas yet with low heat value and amount of methane. Using the technologies including treatment and proper preparation, access to biogas with characteristics similar to natural gas has become conventional (berglund, 2006, pp. 254-266).

Biomass is the fourth energy source after oil, gas and coal providing over $11 \%$ of the required energy for the man. Livestock waste is one of the five sources for biogas production that is considered in the second position after agriculture wastes. Currently, amount of livestock manure has been 74,946 tons per year having about8668 million cubic meters of potential for biogas production. Investigations indicate that U.S with use of existing biogas resources such as dairy industry waste, livestock waste, and energy products enables to produce3 GW electricity with establishment of biogas power plants (Kramer, 2008).

The most important advantages for use of livestock manure are targeted in producing biogas and electricity including removal of odors and sly animals, waste management, energy saving and heat saving(Cuttica,2006). With regard to the latest statistics proposed in 2009, the most superior countries producing energy from biomass resources include United States, Brazil, the Philippines, Germany, Sweden and Finland (Ribeiro Salomon, 2009).

\section{Chemical structure and the way for biogas production}

Biogas is a mixture of three combinations named methane, carbon dioxide and hydrogen sulfide, obtained from anaerobic decomposition and fermentation of biomass by means of Methanogens bacteria. Methane is combustible component in biogas encompassing more share of this gas (60\%$80 \%)$. Methane is a colourless and odourless gas that if a cubic feet of this gas burns, $252 \mathrm{kcal}$ (1052.3 $\mathrm{kJ}$ ) heat energy will be produced, mentioned with a substantial amount compared to other fuel substances. The most important advantage of methane to other fuels lies on this fact that methane does not produce carbon monoxide while burning (Rajakovic, 2006). Biogas production cycle has been represented in figure below.

Livestock Manure Anaerobic Digestion

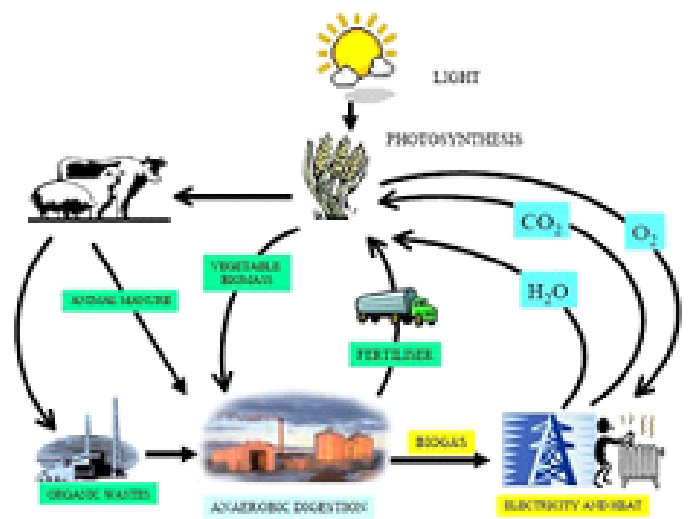

Fig. 1. Biogas production cycle/ Source:

(Rahi \& Garshasbi, 2010, p. 4)

generators have been mentioned as one of the biogas generators. In average, 15 days pass from digestion of animal wastes to obtain biogas. These generators are built as tank at the depth of ground. Placement of generator at the depth of ground causes saving the required space, stabilizing heat and resistance of generator at cold areas, increasing its importance and efficiency. The leading plan of the generator exists in different models including Chinese and Indian models, that the fixed volume in gas tank has been mentioned as the only difference between Chinese and Indian generators, in which use of metal and spring is not seen (Hajari \& Saheb Jamei, 2010, p. 7).

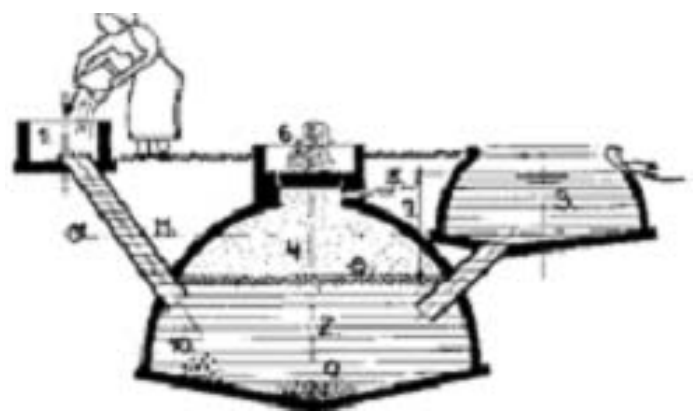

1.Mixing tank with inlet pipe 2.Digester 3.Compensating and removal tank 4.Gasholder 5.Gaspipe 6. Entry hatch, with gastight seal and weighted 7. Difference in level = gas pressure in cm WC 8. Supernatant scum; broken up by varying level 9. Accumulation of thick sludge 10 . Accumulation of grit and stones 11. Zero line: filling height without gas pressure.

Fig. 2. Fixed dome biogas plant- Chinese model/ Source: (BIOGASPLANT, 2015) 


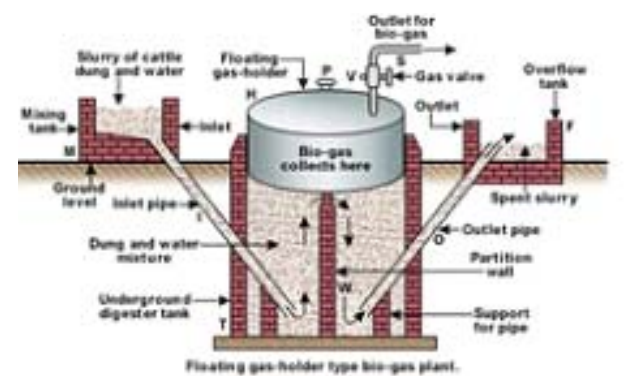

Fig. 3. Biogas generator with fluid lid-Indian model/ Source: (Hajari \& Saheb Jamei, 2010, p. 7)

\section{Role of analogy in meta-form use of architecture matched with animals}

Non-form use of architecture inspired by nature animals has rooted in analogy same as formal analogies and behavioral approaches in animal nests. The ways in which this new type of analogy may happen can be examined with the agents of survival and natural cycles. Survival in nature comes to realize through a natural cycle based on the fig. 4, causing self-efficacy and survival of plants, animals and humans in nature.

In non-from based method for architecture matched with animal lives, analogy with natural cycle and survival happens as if the building, like a living agent, obtains the ability to provide the required energy in a cycle as shown in figure 5 .

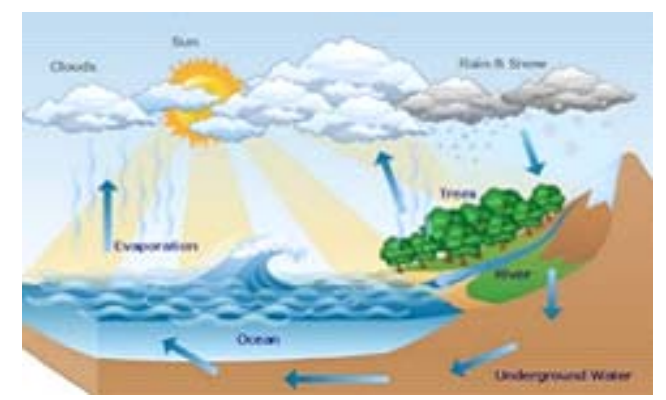

Fig. 4. Nature cycle/ source: (Coceptdraw, 2014)

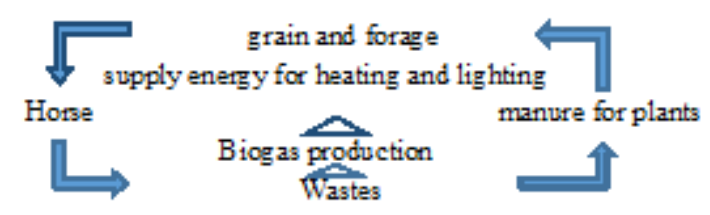

Fig. 5. The cycle for energy supply at riding school buildings/ Source: (Heidari, 2015, p. 99)

\section{CONCLUSION}

Bahamon \& Pérez have classified the architecture matched with nature of animals to four groups: (a) animal anatomical structure, (b) animal constructive structures, (c) social animal constructive structures, and (d) temporary animal structures. This article argued that animal architecture might also be classified into two more general sections categories: analogy with apparent form of animals covering previous groups (1) and (4), analogy with nest of animals' inhabitants including previous groups (2) and (3). The architecture method matched with animals has been used as form-based design in different applications including residential, commercial, cultural and service centers. Use of this method can go not only beyond the mere formal scale, but also for projects functioning for both people and animals such as schools and horse riding centers, livestock, zoos and Animal Care Centre. Use of nature and analogy of animals in today's contemporary architecture rather than visual analogies can be used beyond the only form-based design. Metaform analogy is targeted in putting an emphasis on improvement of combination to a stage in which proper response to programs and functions in line with combination is pursued. Animal wastes in line with biogas production as an energy renewable source provides meta-form use of animal architecture method. Origin of architecture matched with animals may rest on not only on beauty but also proper response to performance and program together with use of structural, natural and behavioral features of animals to induce these features to the sustainability. Indeed, feature differentiates the architecture matched with animals from what proposed previously. In this regards, the architecture matched with animals moves towards self-efficacy and dynamism of building through exploitation from animal wastes, that the general classification for architecture matched with animals is represented in two classifications: formal and informal; behavioral style and apparent form styles in nests have been considered in formal classification and utilization from biogas entitled features ending in natural cycle has been considered in informal classification. Both behavioral method and apparent form methods pass a trend from top to down in sake of processing, 
because an emphasis has been put on the stage of combination in these two methods of architecture matched with animals. Designer extracts the plan in a formal way through the analogy of building with animals, yet the process of design can work out through processing in the method of the features ending in natural cycle. When the designer considers program-based method to meet the needs at program and plan, the processing trends passes from down to top, and when the architect considers the features ending in natural cycle, the processing trend passes from top to down. Role of analogy in design process through animal architecture is clear in each of samples. This research revealed that the form cases can be considered as the analogy with a style of behavioral or apparent form in animal nest-building. Further, analogy with natural cycle has come to realize in informal exploitation from animal architecture indicating importance and role of analogy in the architecture method matched with animals.

\section{REFERENCES}

1. Antoniades, Anthony C, "Poetics of Architecture Theory of Design”, Translated into Persian by Ahmad- reza Ai, Volume II , Soroush (Publications, TV and Radio), Tehran, Iran, 2011.

2. Bahamon, A, Perez, P, "Inspired by Nature Animals”, Barcelona: W.W. Norton \& Company, 2009.

3. Bahamon, Alejandro, Perez, Patricia, “Animal: analogies entre le monde animal et larchitecture contemporaine”, Translated into Persian by Khosro Afzalian, Kasra, Mashhad, Iran, 2011.

4. Berglund, M, Borjesson, P, "Assessment of Energy Performance in the Life- Cycle of Biogas Production", Biomass and Bio-energy 2006; 30

5. Cruz, Cesar A, "Wright's Organic Architecture: From >Form Follows Function< to >Form and Function are One`”, Wolkenkuckucksheim , Cloud-Cuckoo-Land, 2012; 32: 27-36

6. Cuttica , J, “CHP-The Concept”, Midwest CHP Application Center, University of Illinois at Chicago, 2006.

7. Ghobadian, Vahid, "Theories and Concepts in Contemporary Western Architecture”, Eighth Edition, Cultural Research Bureau, Tehran , Iran, 2008.

8. Hajari, Zahra, Saheb Jamei, Nadia, "Production of biogas from sewage and waste”, Iran
Bioenergy Conference, Tehran, Iran, 2010.

9. Heidari, Mozhgan, "Equestrian school approach Review to architectural design based on structure of animals” Islamic Azad University, Central Tehran Branch, Tehran, Iran, 2015.

10. Kramer, J, "Winsconsin Agricultural Biogas Case book”, Prepared for focus on Energy, Energy Center of Wisconsin, 2008.

11. Mahdinejad, Jamalodin, et al, "Architecture design based on the interaction between aesthetics and function in nature", HoviatShahr, Tehran, No. 2012; 10: 59-66

12. Pourtalebi, Shahab, "The necessity of using bio form design process in response to emotional needs of the customer", The 1st National Conference on New Technologies in Home Appliances, Entekhab Higher Education Center, UAST, Entekhab Group, 2012.

13. Rahi, Abbas, Garshasbi, Mahdi, "Technical and statistical study of biogas to generate distributed electricity in Iran", Iran Bioenergy Conference, Tehran, Iran, 2010.

14. Rajakovic, N, Knezevic, M, ”Biogas-Energy Instead of Waste”, Sixth International Symosium Nikola Tesla , Belgrade, SASA, Serbia, 2006.

15. Rezaei, Mahmud, "Design Analytica: Reviewing Theories and Concepts in Contemporary Design Process of Form and Space" Islamic Azad University, Central Tehran Branch, Tehran, Iran, 2014.

16. Ribeiro Salomon, Karina, "Estimate of the electric energy generating”, Potential for different sources of biogas, Biomass and Bioenergy, Brazil, 2009; 33

17. Sadri, Mehdi, Kavandi, Mehdi, Jozepiri, Alireza, Teimouri, Sharareh, Abbasi, Fatemeh, "Bionic Architecture, Forms and Constructions”, Research Journal of Recent Sciences, 2014; 3(3), 93-98

18. Sharghi, Ali, Ghanbaran, Abdolhamid, "The lessons of nature in architectural design", Environmental Science and Technology, 2012; 14(3)

19. Taghizadeh, Katayoun, Bastanfard, Matin, "The Anatomy of a Human Body, a Model to Design Smart High Building”, Science and Technology, 2012; 2(1): 8-14

20. Biogasplant., "Fixed Dome Biogas". Retrieved from build-a-biogas-plant natural and renewable: http://www.build-a-biogas-plant.com, 2015.

21. Coceptdraw, "Cycle diagram software" Retrieved from conceptdraw: http:// www.conceptdraw.com, 2014. 